\title{
INTEGRATING AHP, SWOT AND QSPM IN STRATEGIC PLANNING- AN APPLICATION TO COLLEGE OF BUSINESS ADMINISTRATION IN SAUDI ARABIA
}

\author{
Syed Abdul Malik* \\ Management Department \\ College of Business Administration (CBAK) \\ Salman Bin Abdulaziz University \\ Saudi Arabia \\ Nasser Saad Al Khatani \\ Management Department \\ College of Business Administration (CBAK) \\ Salman Bin Abdulaziz University \\ Saudi Arabia \\ Mohammad Naushad \\ Management Department \\ College of Business Administration (CBAK) \\ Salman Bin Abdulaziz University \\ Saudi Arabia
}

\begin{abstract}
HEIs integrating AHP, SWOT and QSPM in Strategic Planning or strategy formulation, is less likely to overlook or weight inappropriately in deciding which alternative strategies to pursue while considering the key external/internal factors. This paper demonstrates the integration of the qualitative and quantitative techniques, such as SWOT, QSPM, with AHP in crafting the strategy of a business school in Kingdom of Saudi Arabia. As evidenced the proposed model improves upon by integrating AHP while developing a QSPM. It is believed that this model is more objective and robust in terms of crafting a strategy for the HEIs.
\end{abstract}

Keywords: Strategic Planning, Analytical Hierarchy Process, AHP, QSPM, SWOT Analysis, and College of Business Administration

\section{Introduction}

Higher Education Institutions (HEIs) have a significant place in shaping the future of the economy and nation as a whole. It serves the society by moulding engineers, doctors, professors, scientist, policymaker etc. Furthermore, HEIs provide training to the different level of employees, consultancy, research \& development that advances the knowledge base and shapes the perception of the society. Although a wrong strategy selection by HEIs may lead them rudderless in the ever changing higher education field. In contrast to this, a carefully crafted strategy will enable HEIs to recognize and respond to changes that are constantly occurring in its marketplace.

\footnotetext{
${ }^{*}$ Corresponding author
} 
In order to formulate strategy, there are different guidelines and procedures that Strategists use as per their understanding of situations, condition the strategy. Moreover, a major problem in strategic planning is the tendency to make small changes to past successful strategies rather than thinking "Outside the Box" and bringing real creativity to the process.

Almost all strategic planning models stress the importance of an external audit to search for opportunities and threats and internal audit to search for strength and weaknesses (Embry O.H. et. al, 2004). Although the systematic use of more than one quantitative and qualitative tool will enhance the reliability and effectiveness of the strategic plan. This paper demonstrates the integration of the qualitative and quantitative techniques, such as SWOT, Quantitative Strategic Planning Matrix (QSPM), with Analytical Hierarchy Process (AHP) in crafting the strategy of a business school in Kingdom of Saudi Arabia.

\section{Overview of Strategic planning in Business Schools}

Richard Alfred (2006) stated that strategy may be defined as "a systematic way of positioning an institution with its stakeholders in its environment to create value that differentiates it from competitors and leads to a sustainable advantage" (p. 61). Having a strategy, which would include a strategic plan, is not necessary in periods of relative calm, when resources are plentiful, and when there is little competition from outside organizations (Jason J. Chevalier). Though this situation rarely exits today, the environment is relatively more competitive as ever before. HEIs go for the strategic planning usually as part of their Total Quality Management (TQM) implementation, accreditation process, program review process and a part of continuous improvement. Every institution has a strategy in place, be it expressed or implied, that appears in patterns that lie across its purposes, its actions, its resource allocation and/or its programs (Bryson, 1995).

Saudi Arabian economy is poised to be diversified from the oil based to manufacturing and services sectors. Although the main hurdle is that the majority of the workforce in the private sector is expatriates. Thus, education sector has a dual role to play by providing the educated workforce and changing the mindset of the community by educating them. Moreover, the performance of the business sector depends on the output of HEIs; therefore, the strategies could be framed in such a way that could serve the purpose of the nation's policy makers. Strategic planning in a higher institution is a complex process that involves many steps, active participation of the institution's key stakeholders, collection and analyses of quantitative and qualitative data, forecasting, prioritization of issues and plans, planning and allocation of resources and/or budgeting and budget allocations (Joel K. Jolayemi, 2012). 
Crafting an effective strategic plan that will lead HEIs to its dreamed future requires integration of theoretical and analytical tools. Moreover, could fulfil the scientific requirements of development of strategy.

\section{Brief description of tools used in strategic planning}

Developing a strategic plan provides a roadmap for mission achievement, as well as, establishes the foundation for continuous improvement. There are a variety of ways that a business school can develop an effective strategic plan (AACSB). The strategic plan process involves five distinct but related tasks: mission development; goal setting; strategy development and selection; strategy implementation; and evaluation/review/adjustment. The process of continuous improvement requires vigilant attention to the formulation and reformulation of strategies to achieve incremental improvements in all areas of the organization on an ongoing basis.

Many authors have adopted diverse qualitative and quantitative tools for the strategic plan as a whole or any single process of strategic planning. A simple way to determine the strategies is to use a TOWS matrix (Wheelen and Hunger, 2004). This matches the SW to the OT, resulting in suitable strategies.

Yang Li, Sun Guohui \& Martin J. Eppler, (2008) review the factors that enable or impede effective strategy implementation, and survey the state of the art in this domain. Ghamdi Salem, (2005) make an inspection of the tools for strategic planning used by 72 companies in Saudi Arabia. He conducted the survey by taking the 13 most popular tools for strategic planning namely, SWOT analysis, Portfolio analysis, analysis of critical success factors, Porter's five force analysis, experience curve analysis, PIMS analysis, what if analysis, stakeholder's analysis, value chain analysis, benchmarking, product life cycle analysis, cognitive mapping and Delphi technique. Brewer, P. D. Et al., (2000), focus the importance of strategic planning in the business schools by providing a model for the continuous quality improvement in the business schools. Wang Fen \& Forgionne Guisseppi, (2007) provides a framework for the use of balance scorecard technique in the strategic e-business management. Embry, Olice H. , Carter, Fonda L., Fleck Robert, (2004), describes the use of Fred R. David's Strategic Planning Model as utilized by the D. Abbott Turner College of Business (DATCOB) to think "Outside the Box" and increase creative thinking.

One of the world acclaim and powerful tool for multi criteria decision making is Analytical Hierarchy Process (AHP). Although in literature, apart from research works by Kahraman et al. (2008), Kangas et al. (2001), Osuna \& Aranda (2007), and Yuksel \& Dagdeviren (2007), few studies can be cited on the 
application of AHP in strategic planning. These authors focus on the application of AHP for prioritizing the SWOT factors and for evaluating and prioritizing strategic alternatives with respect to the factors during the development of basic strategic plans.

\section{Research Methods}

The researchers integrate AHP, SWOT and QSPM in Strategic Planning at College of Business Administration Al Kharj (CBAK) in Saudi Arabia. Figure 1 shows strategy development process at CBAK. The mission and vision statements provide the two ends of an analytical view of the institution from which the strategic plan is developed. The mission and vision represent the current and envisioned state of the institution (Hinton K. E., 2012). The strategic plan is used to bridge the gap between the two.

\section{SPC-CBAK}

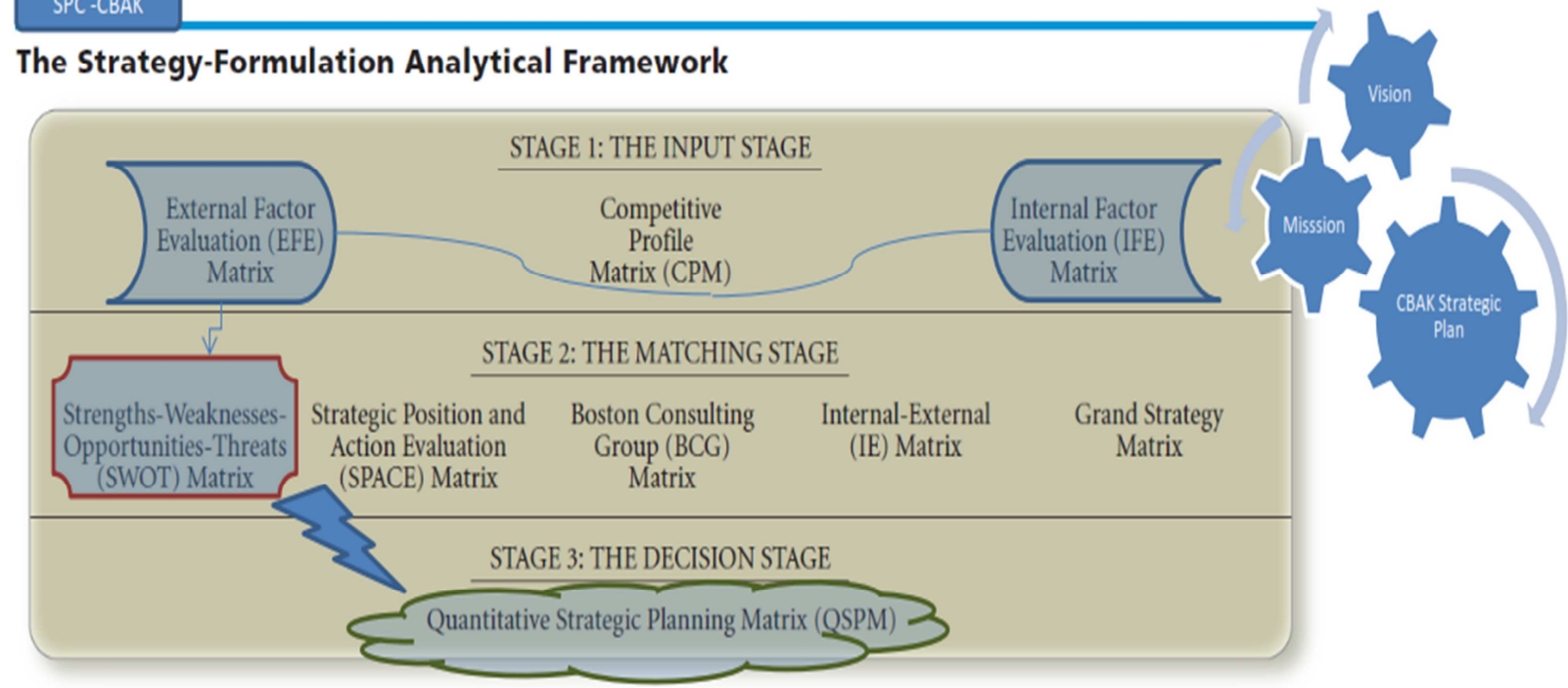

Figure 1 Strategic Planning at CBAK

According to Professor Fred R. David, "An effective process for strategic planning is to develop an EFE Matrix and IFE Matrix followed by a SWOT and BCG and then finally a QSPM.” Following Professor Fred R. David three stage strategy formulation framework, this study integrates AHP in the Input Stage to priorities an EFE Matrix and IFE Matrix. The AHP is an approach for facilitating decision-making by organizing perceptions, feelings, judgments and memories into a multi-level hierarchic structure that exhibits the forces that influence a decision (Saaty, 1994). The AHP method provides a structured framework for setting priorities on each level of the hierarchy using pair-wise comparisons that are quantified using 1-9 scales (Saaty, 1980). 
In the Matching stage a SWOT Matrix for generating feasible strategies that matches key external and internal factors was used.

Finally, QSPM was used in the Decision stage by means of an Attractiveness Score (AS) of 1, 2, 3, or 4 to reveal each strategy's attractiveness given the respective external or internal factor, where 4 is the best and 1 is the least attractive. Thus, decide which strategy is best for CBAK given the respective external or internal factor.

\section{Application of the Integration Model to CBAK Strategic Plan}

In this section, the Integration of AHP, SWOT and QSPM in Strategic Planning is demonstrated by development of a strategic plan for College of Business Administration Al Kharj (CBAK), Salman Bin Abdulaziz University in Saudi Arabia.

CBAK, established in the year 2008, has six academic departments which currently offer Bachelor of Science in Business Administration (BSBA) with a major in the field of Accounting, Finance, Human Resource Management, Management Information System, Management, and Marketing. CBAK is led by a visionary Dean who believes in innovative ideas and provides support to faculty, staff and students in order to achieve the organizational mission and outcomes. While being aware of the nature of its regional environment and the scarcity of its resources, the CBAK is an organization that seeks a competitive advantage at both the regional and national levels. With respect to quality assurance and programs development, CBAK considers regional and international accreditation requirements and refers to international benchmarks (e.g.; curriculum; programs specification; course specification; course plans; syllabuses). The following are the vision, mission and values:

Vision: To Become a Prominent College in the Region in Business Education and Community Partnership

Mission: College of Business Administration at Al-Kharj endeavors to develop principled, innovative and competent business professionals in an environment of academics, research, and community partnership. This is accomplished through the alignment with national and international academic standards.

As a core constituent of Salman Bin Abdulaziz University, CBAKs Values explain what the college stands for and the way in which it intends to conduct its activities. The following are CBAKs Values: Quality, Innovation, Islamic Ethics and Beliefs, Collaboration and Shared Governance, Transparency and Accountability.

\section{Stage 1: The Input Stage}


The CBAK Strategic Planning Committee (consisting of CBAK Dean, Assistant Dean for Quality \& Development, Senior Consultant, Professors, Heads of Academic Departments and a Student representative) first conducted an internal and external audit by administering a survey to a broad range of stakeholders i.e. teaching staff, students, and board of advisors from industry and alumni of CBAK. The survey was essentially a SWOT analysis, asking for views on the CBAKs Strengths, Weaknesses, Opportunities and Threats. This resulted in generating SWOT factors which are based on the stakeholders' perspective and not what the SPC thinks or perceives it.

In the next step, Strategic Planning Committee (SPC) integrated the Analytical Hierarchy Process (AHP). First, each of the four groups' comparisons was carried out in pairs among the SWOT factors. SPC member`s task was to compare two factors with respect to the goal (Development of the best strategic plan for the college). Each question included ranking on a scale of 1 to 9 (Saaty scale) in order to make relative judgment factors. These comparisons were used as input to calculate the local priorities of the factors using the method of eigen values described by Saaty (Refer Appendix 1). The resulting priorities and ranking factors are depicted in the tables $1-4$.

Table 1. Strengths

\begin{tabular}{|c|c|c|}
\hline Criterion & Weights & $\mathbf{R k}$ \\
\hline S1 Strong Leadership & $25.0 \%$ & 1 \\
\hline S2 Enthusiastic Instructors & $18.9 \%$ & 3 \\
\hline S3 Good location and modern infrastructure & $8.4 \%$ & 5 \\
\hline S4 Up to date teaching equipment and technology & $10.3 \%$ & 4 \\
\hline S5 Existence of wide choices of programs of study & $6.2 \%$ & 7 \\
\hline S6 Existence of a business center & $4.4 \%$ & 8 \\
\hline S7 Existence of ICT & $6.6 \%$ & 6 \\
\hline S8 Existence of QAU & $20.1 \%$ & 2 \\
\hline
\end{tabular}




\begin{tabular}{|c|c|c|c|}
\hline & Criterion & Weights & $\mathbf{R k}$ \\
\hline W1 & Students have difficulties communicating in English & $33.0 \%$ & 1 \\
\hline W2 & Shortage of Teaching Staff and Lack of wide range of faculty's expertise & $18.4 \%$ & 2 \\
\hline W3 & $\begin{array}{l}\text { Non-availability of systematic and effective academic guidance service to } \\
\text { students }\end{array}$ & $7.8 \%$ & 5 \\
\hline W4 & $\begin{array}{l}\text { Absence of an effective electronic mean of communication between } \\
\text { faculties and students (e.g.; outlook express; other software) }\end{array}$ & $6.2 \%$ & 7 \\
\hline W5 & $\begin{array}{l}\text { Library and other learning resources are inadequate and no fulltime access } \\
\text { to library }\end{array}$ & $7.6 \%$ & 6 \\
\hline W6 & Dearth of independent financial resources and external fund raising & $4.9 \%$ & 8 \\
\hline W7 & $\begin{array}{l}\text { Facilities are inadequate for extracurricular activities (including sporting and } \\
\text { recreational activities) }\end{array}$ & $8.0 \%$ & 4 \\
\hline W8 & $\begin{array}{l}\text { Absence of formal faculty mentoring program, regular conferences, external } \\
\text { seminars and workshops }\end{array}$ & $14.1 \%$ & 3 \\
\hline
\end{tabular}

Table 3. Opportunities

\begin{tabular}{|l|c|c|}
\hline \multicolumn{1}{|c|}{ Criterion } & Weights & Rk \\
\hline O1 $\begin{array}{l}\text { Creation of continuing education program, MBA program, } \\
\text { executive program, joint programs with international partner } \\
\text { universities and online programs }\end{array}$ & $20.4 \%$ & 2 \\
O2 $\begin{array}{l}\text { Development of an undergraduate experience using the best } \\
\text { practices (international standards) }\end{array}$ & $7.1 \%$ & 6 \\
O3 $\begin{array}{l}\text { Being strategically located close to the Riyadh- Kharj } \\
\text { industry zone }\end{array}$ & $8.2 \%$ & 5 \\
O4 $\begin{array}{l}\text { More interactions and partnerships with local employers in } \\
\text { the private, nonprofit, and public sectors } \\
\text { Partnership and networking with similar faculties and colleges } \\
\text { locally and globally }\end{array}$ & $24.9 \%$ & 1 \\
O6 $\begin{array}{l}\text { Potential revenue generation through consulting and training } \\
\text { O7 Recruitment of diverse and competent faculties }\end{array}$ & $4.2 \%$ & 8 \\
O8 Potential for research activities & $7.0 \%$ & 7 \\
\hline
\end{tabular}

\section{Table 4. Threats}

\begin{tabular}{|l|c|c|}
\hline \multicolumn{1}{|c|}{ Criterion } & Weights & Rk \\
\hline T1 Difficulty of attracting distinguished faculty & & \\
$\quad$ members in certain academic disciplines & $30.0 \%$ & 1 \\
T2 Risk of losing prominent faculty and staff & $15.4 \%$ & 3 \\
T3 Tough competition among colleges to attract top & & \\
$\quad$ students & $17.0 \%$ & 2 \\
T4 Potential decrease of students' retention & $12.8 \%$ & 5 \\
T5 Growing pressure to enroll increasing numbers of & & \\
$\quad$ students in some disciplines & $12.0 \%$ & 6 \\
T6 Financial incentives provided by the private & $12.8 \%$ & 4
\end{tabular}




\section{Stage 2: The Matching Stage}

In this stage, Fred R. David's SWOT Matrix (see Table 5) was used to match and develop four types of strategies. SWOT matrix is composed of two-dimensional coordinates of a chart; it indicates that each of the four areas is a strategy. These strategies include (Karppi et al, 2001):

$>$ Aggressive or Maxi-Max strategies (SO): maximum use of environmental opportunities using the organization's strengths.

$>$ Conservative or Mini-Max strategy (WO): strategies of potential benefit that lies in environmental opportunities, to compensate for the weaknesses of the organization.

$>$ Competitive or Maxi-Min strategies (ST): The strategy of the organization's strengths to avoid threats facing

$>$ Defensive or Mini-Min strategies (WT): a strategy for minimizing losses due to threats and weaknesses

The strategic planning committee was able to use the TOWS matrix successfully during a retreat, thereby set forth the following six goals to accomplish CBAKs mission and vision during a five year cycle:

Goal 1: Develop ideas, knowledge and skills by honing intellectual opportunities

Goal 2: Enhance the functioning of student centric services

Goal 3: Motivate and satisfy the students, faculty and staff members

Goal 4: Enhance the quality and development process

Goal 5: Foster the healthy relationship with the stakeholders

Goal 6: Create a conducive environment for research and graduate programs

For the above six Goals, Fred R. David's SWOT Matrix is used to match and develop four types of strategies as depicted in table 5 .

Table 5. SWOT Matrix

\begin{tabular}{|c|c|c|}
\hline External Factors & $\begin{array}{c}\text { Strengths (S) } \\
\mathrm{S} 1, \mathrm{~S} 2, \mathrm{~S} 3, \mathrm{~S} 4, \mathrm{~S} 5, \mathrm{~S} 6, \mathrm{~S} 7 \text { and S8 }\end{array}$ & $\begin{array}{c}\text { Weaknesses (W) } \\
\text { W1, W2, W3, W4, W5, W6, W7 } \\
\text { and W8 }\end{array}$ \\
\hline 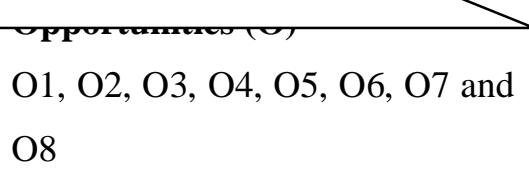 & SO & WO \\
\hline $\begin{array}{l}\text { Threats }(\mathbf{T}) \\
\mathrm{T} 1, \mathrm{~T} 2, \mathrm{~T} 3, \mathrm{~T} 4, \mathrm{~T} 5 \text { and T6 }\end{array}$ & ST & WT \\
\hline
\end{tabular}




\section{S. Abdul Malik et al./ Application to college of business administration}

\section{Stage 3: The Decision Stage}

Finally in this stage, using Quantitative Strategic Planning Matrix (QSPM) by using an Attractiveness Score (AS) of 1, 2, 3, or 4 to reveal each strategy's attractiveness given the respective external or internal factor, where 4 is the best and 1 is the least attractive. Thus, decide which strategy is best for CBAK given the respective external or internal factor.

\section{Table 6. Quantitative Strategic Planning Matrix (QSPM)}

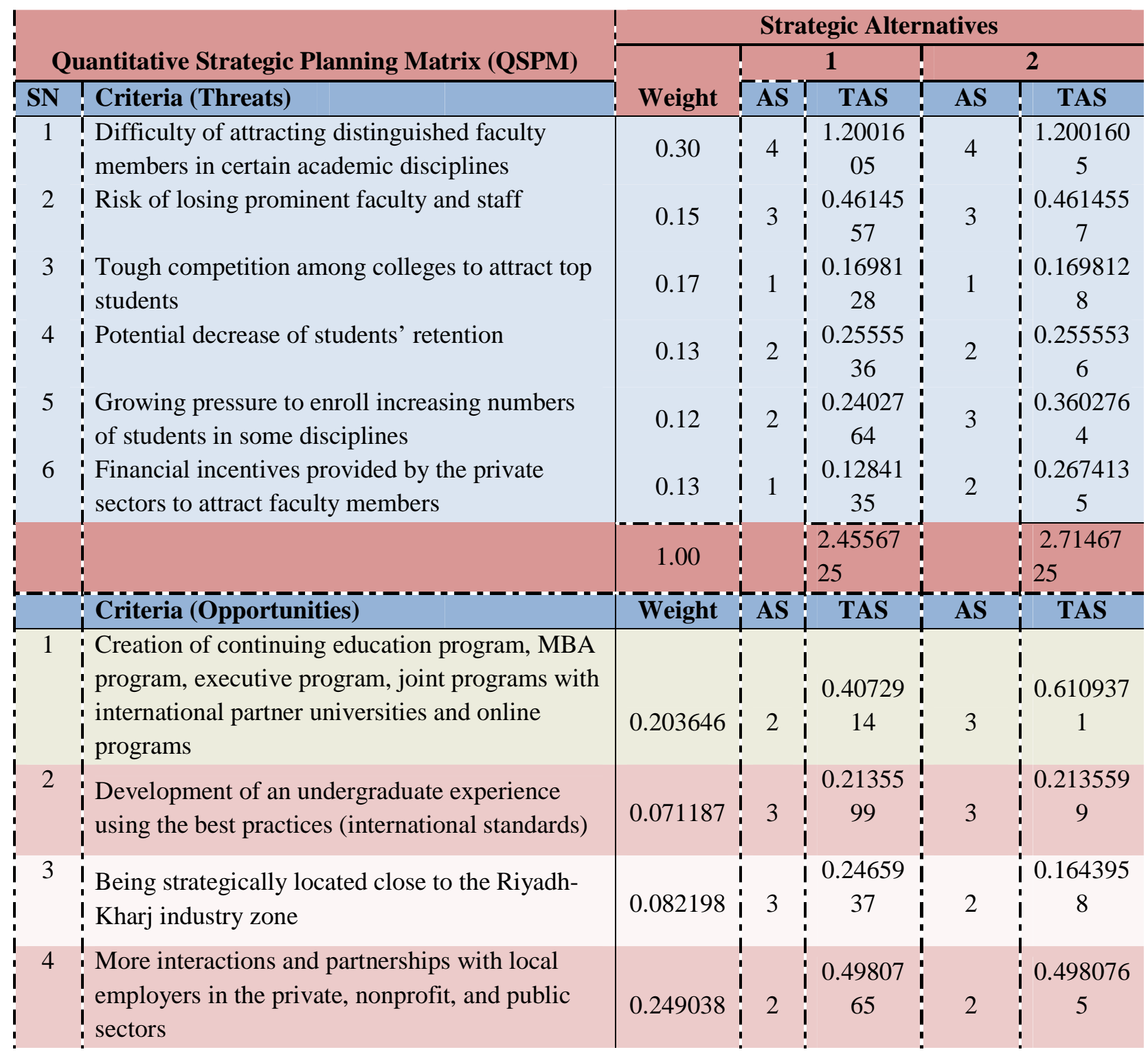




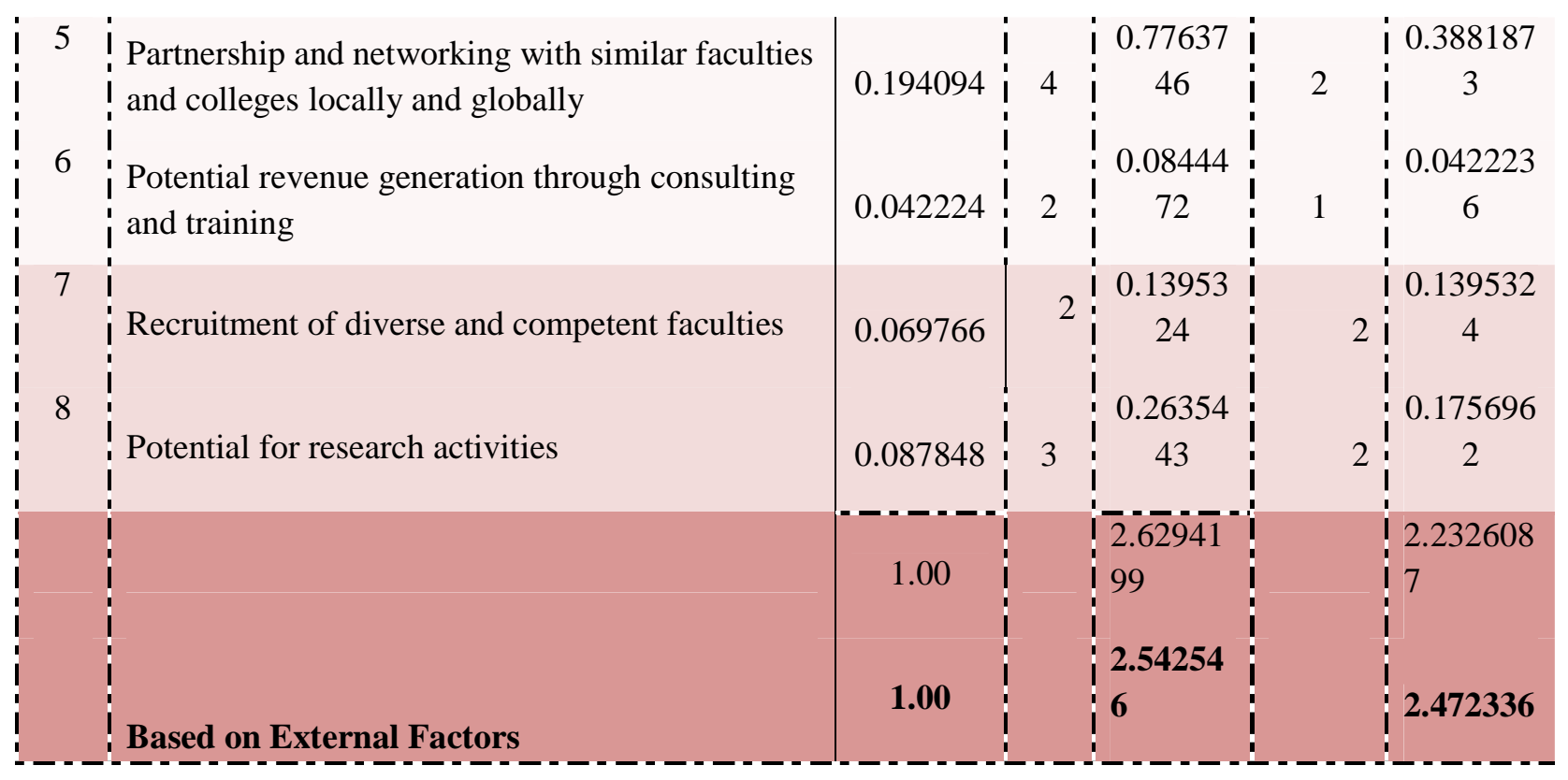

Note that an Attractiveness Score (AS) of 1, 2, 3, or 4 is used to reveal each strategy's attractiveness given the respective external or internal factor, where 4 is the best and 1 is the least attractive. Work row by row in developing the QSPM and decide which strategy is best given the respective external or internal factor. Assign a 4 to the best strategy. An Attractiveness Score on an average based on External factors is depicted as 2.54 and 2.47 respectively for the two alternative strategies. It indicates that the strategic alternative no. 1 is more preferable from the external points of view than the other. Similarly the Attractiveness Score from the point of Internal factors is ascertained to deicide about the two strategic alternatives. In the final stage the average Attractiveness Score considering both the internal and external factors will give the best strategy to accomplish CBAKs mission.

\section{Conclusion}

A well designed and implemented strategic planning process can provide an institution with a forum for campus-wide conversations about important decisions. The process can also be organized to make assessment, resource allocation, and accreditation easier, and be a source of information about progress and achievement with very real meaning to those associated with the institution (Hinton K. E., 2012). Thus, Higher Education Institutions (HEIs) integrating AHP, SWOT and QSPM in Strategic Planning or strategy formulation, is less likely to overlook or weight inappropriately in deciding which alternative strategies to pursue while considering the key external/internal factors. As evidenced our integrated model 
improves upon by integrating AHP while developing a QSPM. We believe our model is more objective and robust in terms of crafting a strategy for the HEIs.

\section{References}

AACSB (2010), “Accreditation Effective strategic planning”, e-newsline, Apr-May, 2010 p-1.

Brewer, Peggy D; Brewer, Virgil L; Hawksley, Michael, (2000) Mid- Atlantic Journal of Business; 36, 2/3; Proquest Central pg.123.

Bryson, J. M. (1995). Strategic planning for public and nonprofit organizations: A guide to strengthening and sustaining organizational achievement. San Francisco, CA: Jossey-Bass.

Chevalier, J. J. (2010). Planning for excellence: A case study of the execution of strategic planning practices on a California community college campus. Proquest.

Fen, W. (2007). Ebbsc: A balance score card- based framework for strategic e-business management. International Journal of e-business Research, 3 (1).

Ghamdi, Salem (2005), "The use of strategic Planning Tools and techniques in Saudi Arabia: An Empirical Study" International Journal of Management, Vol.22, No.3.

Hinton, Karen E. (2012) “A Practical Guide to Strategic Planning in Higher Education" Society for College and University Planning, Retrieved from http:// www.scup.org

Kahraman, G., N.C. Demirel, T. Demirel \& Y.N. Ates (2008). A SWOT-AHP application using fuzzy concept: EGovernment in Turkey. In Gengiz Kahraman (Eds), Fuzzy Multi-Criteria Decision Making : Theory and Applications with Recent Developments (pp. 85-117). US: Springer.

Kangas, J., M. Pesomen, M. Kurtila \& M. Kajanus (2001). “A'WOT: Integrating AHP with SWOT analysis.

Proceedings of the Sixth International Symposium on the Analytic Hierarchy Process, 189-198.

Jolayemi, J. K. (2012). On the Application of Analytic Hierarchy Process in Institution-Wide Strategic Planning. Academy of Strategic Management Journal, 11 (2).

Olice, E. H., Carter, L. F., \& Robert, F. (2004). College of Business Strategic Planning "Outside the Box". Proceedings of the Academy of Educational Leadership, 09.

Richard, A. L. (2005). In Managing the Big picture in Colleges and Universities: form Tactics to strategy. Greenwood Publishing.

Osuna, E. E. \& A. Aranda. (2007). Combining SWOT and AHP techniques for strategic planning. Proceedings of the 9th International Symposium on the Analytic Hierarchy Process.

Saaty, T.L. (1980). Multicriteria decision making: The analytic hierarchy process (First Edition).New York: McGraw-Hill.

Saaty, T.L. 1994, Fundamentals of the Analytic Hierarchy Process, RWS Publications, 4922

Ellsworth Ave., Pittsburgh, Pennsylvania 
Wheelen, T. L. and Hunger, D. J. (2004); "Strategic Management and Business Policy", 9th Edition, 2004, Pearson Prentice Hall, pp. 69 - 74.

Yang Li, Sun Guohui \& Martin J. Eppler, (2008) "Making Strategy Work: A Literature Review on the Factors influencing Strategy Implementation" ICA Working Paper 2/2008.

Yuksel, I. \& M. Dagdeviren (2007). Using the analytic network process in a SWOT analysis - A case study of a textile firm. Information Sciences: An International Journal, 177(16), 3364-3382. 


\section{Appendix 1}

\section{Analytical Hierarchy Process (AHP)}

Only input data in the light green fields and worksheets!
$\mathbf{n}=8$ Number of criteria (3 to 10 )
Linear
$\mathbf{N}=5$ Number of Participants (1 to 10 )
$44.8 \%$
$\mathbf{p}=1$ selected Participant $(0=$ consol. $)$
Abdul Ma

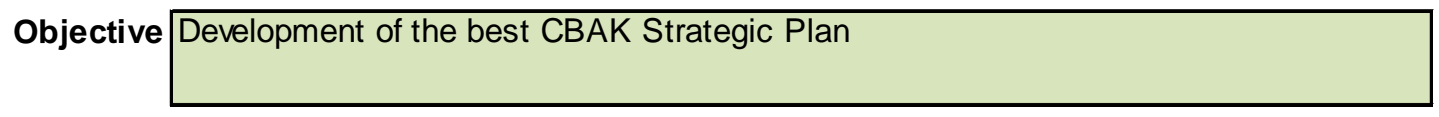

Author CBAK-SPC

\begin{tabular}{|c|c|c|c|c|c|}
\hline \multirow{3}{*}{ Date } & \multicolumn{3}{|c|}{ 4-May-13 } & & $-2.89 \mathrm{E}-14$ \\
\hline & \multicolumn{4}{|c|}{ Criterion } & Weights \\
\hline & \multicolumn{4}{|c|}{$\begin{array}{l}1 \text { Creation of continuing education program, MBA program, executive prog } \\
2 \text { Development of an undergraduate experience using the best practices (i } \\
3 \text { Being strategically located close to the Riyadh- Kharj industry zone } \\
4 \text { More interactions and partnerships with local employers in the private, n } \\
5 \text { Partnership and networking with similar faculties and colleges locally an } \\
6 \text { Potential revenue generation through consulting and training } \\
7 \text { Recruitment of diverse and competent faculties } \\
8 \text { Potential for research activities }\end{array}$} & \begin{tabular}{|l|}
$20.4 \%$ \\
$7.1 \%$ \\
$8.2 \%$ \\
$24.9 \%$ \\
$19.4 \%$ \\
$4.2 \%$ \\
$7.0 \%$ \\
$8.8 \%$ \\
\end{tabular} \\
\hline Matrix & & 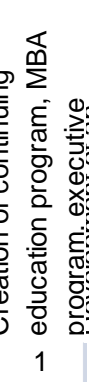 & 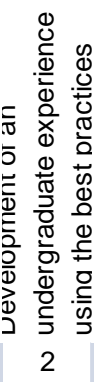 & 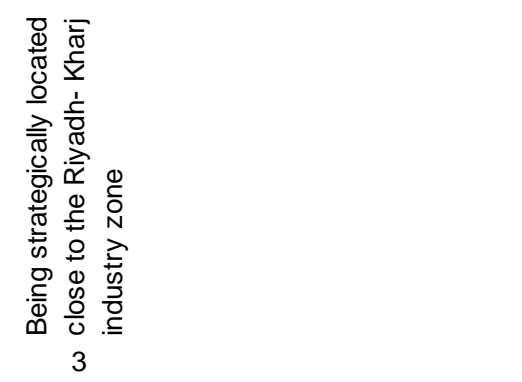 & $\begin{array}{r}\text { normaliz } \\
\text { ed } \\
\text { principal } \\
\begin{array}{r}\text { Eigenve } \\
\text { ctor }\end{array}\end{array}$ \\
\hline $\begin{array}{l}\text { Creation of } \\
\text { continuina }\end{array}$ & $(1$ & & 9 & 2 & $(20.4 \%)$ \\
\hline $\begin{array}{r}\text { Development } \\
\text { of an }\end{array}$ & 2 & $1 / 9$ & 1 & 3 & $7.1 \%$ \\
\hline $\begin{array}{r}\text { Being } \\
\text { strateaicallv }\end{array}$ & 3 & $1 / 2$ & $1 / 3$ & 1 & $8.2 \%$ \\
\hline $\begin{array}{r}\text { More } \\
\text { interactions }\end{array}$ & 4 & & 8 & 6 & $24.9 \%$ \\
\hline $\begin{array}{r}\text { Partnership } \\
\text { and }\end{array}$ & 5 & $1 / 3$ & $1 / 3$ & 5 & $19.4 \%$ \\
\hline $\begin{array}{l}\text { Potential } \\
\text { revenue }\end{array}$ & 6 & $1 / 9$ & 3 & $1 / 6$ & $4.2 \%$ \\
\hline $\begin{array}{c}\text { Recruitment } \\
\text { of diverse }\end{array}$ & 7 & & 5 & $1 / 5$ & $7.0 \%$ \\
\hline $\begin{array}{r}\text { Potential for } \\
\text { research }\end{array}$ & 8 & $1 / 9$ & 5 & $1 / 3$ & $8.8 \%$ \\
\hline
\end{tabular}

